Mirai. Estudios Japoneses

ISSN-e: 1988-2378

http://dx.doi.org/10.5209/MIRA.57106

\title{
Libros japoneses para turistas extranjeros (de la era Meiji a la II Guerra Mundial)
}

\author{
V. David Almazán Tomás ${ }^{1}$
}

Resumen: Desde la apertura de Japón en la era Meiji (1868-1912) los viajeros occidentales publicaron libros y guías de viaje con sus impresiones y recomendaciones. Desde muy pronto, Japón fue consciente de la necesidad de proyectar una imagen atractiva, pero documentada, de sus costumbres, su arte, su arquitectura, su folklore, sus festividades, etc. Los impresos japoneses dedicados a los turistas extranjeros son un material de gran interés para conocer tanto los elementos culturales con los que Japón se siente identificado, como los temas y lugares potencialmente atractivos para los occidentales. Las principales características de estos primeros libros son que fueron escritos por japoneses muy competentes en las materias tratadas y que fueron publicados en Japón en lenguas occidentales, especialmente en inglés. Respecto a los editores de estas iniciativas, hemos de constatar que las acciones de promoción del turismo japonés y la publicación de impresos fue una labor emprendida conjuntamente por la iniciativa pública y privada, que compartían intereses. Así se constata en los impresos del The Welcome Society of Japan, Japan Tourist Bureau y de la Imperial Government Railways. Sin duda, una colección de excepcional interés fue la Tourist Library que exquisitamente editó el comité Board of Tourist Industry y el Japanese Governmet Railways. También las empresas hoteleras se destacaron por su labor de difusión del Patrimonio Cultural mediante libros con muy cuidadas ediciones, siendo monumental y casi enciclopédica su descripción de costumbres, modas, ceremonias, festivales, artes y un sin fin de temas que, desde 1934, editó el Hotel Fujiya con el título We Japanese.

Palabras clave: Patrimonio cultural; guía de viaje; turismo.

\section{[en] Japanese books for foreign tourists (from the Meiji era to the Second World War)}

Abstract: From the Meiji era (1868-1912), Western travellers to Japan published books and guidebooks recording their impressions and recommendations of their experience there. From an early stage, the Japanese became aware of the need to offer an attractive, but documented, image of its customs, art, architecture, folklore, festivities, etc. Japanese printed works aimed at foreign tourists are a great source of information about the cultural elements with which Japan identifies itself, as well as the topics and locations potentially attractive for Westerners. The main features of these first books are that they were written by Japanese, proficient in the topics they addressed, and that they were published in Japan in foreign languages, mainly English. Regarding the publishers, it is necessary to highlight that the promotion of tourism and the publishing of these texts was a joint private-public enterprise, as can be seen in the printed works published by The Welcome Society of Japan, the Japan Tourist Bureau and the Imperial Government Railways. Without any doubt, an exceptional collection was the "Tourist Library", which was superbly edited by the Board of Tourist Industry and the Japanese Government Railways. Hotel companies also played an important role in the promotion of cultural heritage with detailed publications, among which the work We Japanese published by Hotel Fujiya from 1934, offered an almost encyclopaedic description of customs, fashion, ceremonies, festivals, arts and an endless list of topics.

Keywords: Cultural heritage; travel guide; tourism.

1 Proyecto I+D HAR2014-55851-P. Grupo “Japón” S-117, Gobierno de Aragón-Universidad de Zaragoza. almazan@unizar.es 
Sumario. 1. El turismo en Japón, desde la era Meiji a la II Guerra Mundial. 2. Libros japoneses para turistas extranjeros. 2.1. Tourist Library. 2.2. We Japanese. Conclusiones.

Cómo citar: Almazán Tomás, V. D. (2017). Libros japoneses para turistas extranjeros (de la era Meiji a la II Guerra Mundial) (2017), en Mirai. Estudios Japoneses 1, 2017, 123-131.

\section{EI turismo en Japón, desde la era Meiji a la II Guerra Mundial}

Desde una perspectiva histórica el origen del turismo internacional en Japón se inicia en la era Meiji (1868-1912), coincidiendo con el final de la época de aislamiento del periodo Tokugawa y la apertura hacia Occidente. Hay bastantes puntos en común entre los primeros viajeros y los actuales, si bien hoy la información turística fluye por internet mientras que antes lo hacía en papel. En nuestros días las aplicaciones para teléfono móvil, las páginas web, los blogs y otras iniciativas en internet, tanto públicas como privadas, informan de todo lo que un viajero requiere. Y por supuesto las guías de viaje siguen editándose, cada vez más ilustradas. Gran parte de las informaciones destacadas, las que podríamos considerar que forman parte del recorrido del Japón tradicional, presentan una gran continuidad con los libros de información turística que se publicaron en Japón para los viajeros occidentales a finales del siglo XIX y la primera mitad del siglo XX. En conjunto, son una excelente fuente para analizar cómo Japón ha querido presentarse al mundo y cómo el mundo ha querido ver a Japón: un museo vivo de tradiciones que conforman un carácter nacional único y de gran interés.

Por su historia y ubicación geográfica, Japón se incorporó tarde al abanico de destinos para los turistas occidentales y las publicaciones dirigidas a ellos se retrasan a la segunda mitad del siglo XIX. Anteriormente, en el periodo Edo, la potente industria editorial japonesa fue capaz de editar eficaces descripciones gráficas sobre viajes, vistas famosas y peregrinaciones religiosas ${ }^{2}$. Así, por citar un ejemplo antiguo, se editaron detallados mapas de bolsillo desplegables, de más de nueve metros, como Dainihon Dōchū Kōtei Saikenki Taizen de $1837^{3}$. Ya en era Meiji todo este tipo de impresos en japonés se multiplicaron, pero aparecieron también publicaciones destinadas específicamente a los turistas occidentales.

2 Por una parte en 1643 Hayashi Gahō estableció las “Tres vistas de Japón”: Matsushima, Amanohashidate y Miyajima, un itinerario que todavía hoy se considera imprescindible para adentrarse en la esencia del patrimonio natural y cultural de Japón. Además existía la tradición de los meisho o lugares famosos, aplicados a parajes de inspiración poética o sitios de relevancia en las ciudades y principales carreteras, como el Tōkaidō, siendo un tema de gran éxito en el grabado ukiyo-e. En este sentido, gracias a artistas como Katsushika Hokusai (17601849) o Andō Hiroshige (1797-1858), este tema es bien conocido fuera de Japón gracias al notable éxito de estos paisajistas. En el ámbito de la literatura la ruta fue el escenario de populares novelas, como la recientemente traducida al español Viaje por el Tōkaidō del escritor Jippensha Ikku (1765-1831).

3 Ciertamente este tipo de formato no es novedoso y existen testimonios desde la Edad Media en Europa con mapas de itinerarios hacia Roma, Jerusalén o Santiago de Compostela. Lo interesante en el caso japonés es la adaptación de formato por parte de la industria editorial mediante grabados xilográficos. En Europa, el grabado calcográfico, también permitió la difusión de grandes guías lineales como la Britania (1675) de John Ogilby. Ya en el siglo XVIII aparecieron guías de bolsillo, como A pocket guide to the English traveler (1719) de Thomas Gardner. Para una visión panorámica de este tema, LóPEz VílchEZ, Inmaculada (2015): “Convenciones gráficas: de la Tabula Peutingeriana a la guía de viaje". En: AA.VV.: Dibujo y Territorio: cartografia, topografía, convenciones gráficas e imagen digital. Madrid: Cátedra, pp. 243-279. 
Desde la era Meiji a la Segunda Guerra Mundial los viajeros occidentales publicaron libros y guías de viaje con sus impresiones y recomendaciones ${ }^{4}$. Quizá Things Japanese (1890) de Basil Hall Chamberlain (1850-1935) ejemplifique perfectamente el extenso repertorio de cuestiones que podían sorprender al visitante. La obra de Chamberlain es un listado alfabético de temas y curiosidades necesarias para el viajero que llega a Japón y quiere acercarse a su cultura ${ }^{5}$. Junto con esta singular obra hay numerosos títulos de diferentes autores que presentaron Japón con planteamientos más convencionales, como el itinerario de un viaje o el desarrollo analítico de unos cuantos apartados específicos como la historia, geografía y costumbres de Japón ${ }^{6}$.

\section{Libros japoneses para turistas extranjeros}

Desde muy pronto los propios japoneses fueron conscientes de la necesidad de proyectar una adecuada imagen de su identidad cultural con información de calidad. Los impresos japoneses dedicados a los turistas extranjeros son un material de gran interés para conocer tanto los elementos culturales con los que Japón se sentía, y sigue sintiéndose, identificado. Como la lengua era un gran obstáculo estas guías fueron editadas generalmente en inglés y, además, solían ser ilustradas, concentrando en algunos monumentos o lugares un ideario del patrimonio cultural japonés, como por ejemplo el Gran Buda de Kamakura ${ }^{7}$.

Los primeros turistas disponían de una información que se basaba fundamentalmente en impresos. El turismo de extranjeros occidentales generó diversos tipos de impresos, muchos de ellos efímeros, como folletos, planos y pequeñas guías, pero también generó libros. Estos libros, para viajeros exigentes que quieren documentarse bien, recogen de una manera completa, ordenada y sugerente los principales aspectos de la cultura. Algunos tempranos ejemplos de publicaciones orientadas a los occidentales fueron guías escritas en japonés, pero con portadas, subtítulos y algunas breves inscripciones en inglés. Por el desconocimiento del idioma japonés, el interés de este tipo de libros para la mayoría de los turistas radicaba en la profusión de ilustraciones. Uno de los casos más interesantes por el tamaño de estas ilustraciones fue Nihon meisho zue. Tōkaidō zoku no bu. Illustrated guide book for travellers round Japan (1889) de B. Ueda y T. Aoki, publicado en Osaka por la editorial Suzandō. En sus 165 páginas aparecían grabados xilográficos con un aspecto parecido al de las revistas occidentales que proporcionaban información visual sobre las ciudades, las estaciones de tren, el monte Fuji, templos, hoteles, playas, baños termales, teatros e, incluso, barrios de placer con el explícito título de "The prostitute quater of

4 Una reciente selección de estudios sobre este tema se recogen en GARCÉs, Pilar / Terrón, Lourdes (eds.) (2013): Itinerarios, viajes y contactos Japón-Europa. Berna: Peter Lang.

5 Este libro ha sido traducido al español como Cosas Japonesas por José Pazó Espinosa para la editorial Satori, completando así la labor iniciada por su bisabuelo Gonzalo Jiménez de la Espada (1874-1938) a comienzos del siglo XX.

$6 \quad$ El interés de estos materiales es desigual y su fortuna crítica también. En mi opinión, desde una perspectiva del estudio de la cultura de masas, son más relevantes aquellos títulos que tuvieron mayor difusión y que presentan ilustraciones.

7 Almazán Tomás, V. David (2013): "La construcción visual de Japón desde Occidente: el Gran Buda de Kamakura como monumento turístico". En: GARCÉs, Pilar / TERRón, Lourdes (Eds.): Itinerarios, viajes... op.cit., pp. 49-64. 
Yoshiwara". Entre los hoteles aparecía un grabado del Fujiya Hotel Miyanoshita, al que nos referiremos a continuación. No obstante este tipo de materiales solamente podía ser complementario para aquellos turistas que no dominaban la lectura del idioma japonés y pronto se vio la necesidad de proporcionar a los visitantes informaciones en lenguas europeas. Aunque desde las primeras décadas de la era Meiji se editaron en Japón libros comerciales ${ }^{8}$ en lenguas occidentales, la mayor parte de las publicaciones turísticas para extranjeros escritas por japoneses se publicaron ya en el siglo XX y a medida que la centuria avanzaba se observó un incremento del uso de imágenes, especialmente fotografías.

Estas publicaciones para occidentales estaban en la línea de la política japonesa de las últimas décadas del siglo XIX. El gobierno del emperador Meiji se coordinó con el mundo empresarial del ferrocarril y los hoteles para fomentar el turismo como un sector de la moderna economía japonesa. La industria hotelera, con fastuosos edificios occidentales con todas las comodidades, eran una pieza clave para que el turista decimonónico disfrutara de Japón. Por otra parte, si bien el viaje hasta Japón se hacía por barco vía Yokohama o Kobe, ya dentro del país era necesaria una potente red ferroviaria para que el turista se moviera por el interior. Las infraestructuras ferroviarias, en pleno desarrollo y expansión, permitieron que los turistas organizaran con comodidad sus itinerarios por Japón ${ }^{9}$. Respecto a los promotores de estas iniciativas, hemos de constatar que las acciones de promoción del turismo japonés y la edición de impresos fue una labor emprendida tanto por iniciativas públicas y privadas, que compartían intereses. Estos importantes agentes (gobierno, ferrocarril y hostelería) fueron los protagonistas de la edición de las principales guías turísticas para extranjeros. En este sentido estos agentes fueron conscientes de que el principal atractivo para el desarrollo de turismo japonés era su rico patrimonio cultural. Así se constata en los impresos del Japan Tourist Bureau, del Japanese Government Railways o del Hotel Fujiya que comentaremos seguidamente.

Los orígenes de las organizaciones gubernamentales para desarrollar el turismo arrancan del gobierno de Itō Hirobumi (1841-1909), quien en 1887 propició la creación de una sociedad llamada Kihinkai, cuyas actividades comienzan a desarrollarse con intensidad desde la última década del siglo XIX. Con el apoyo del gobierno, comenzó siendo dirigida por el Shibusawa Eiichi (1840-1931), gran impulsor del capitalismo, y contaba con el prestigio de los altos diplomáticos y la aristocracia ${ }^{10}$. La creación de la Kihinkai, más conocida por su denominación The Welcome Society of Japan, supuso que se iniciara la publicación de impresos en inglés para turistas occidentales. A finales del XIX editaban un panfleto desplegable con una mujer hermosa en portada, que tenía en su interior un gran mapa de Japón, unas breves notas cultu-

8 Por la extensión de este texto y la orientación de la publicación en el turismo, dejamos a un lado un interesante apartado de publicaciones, las emprendidas por T. Hasegawa en Tokio en la era Meiji sobre cuentos y leyendas japonesas, así como otros títulos, los cuales sirvieron muchas veces como suvenir turístico y como fuente de información en lenguas europeas de tradiciones y costumbres japonesas, pero que no tenían una marcada orientación de guías turísticas y que, además, fueron redactadas por extranjeros residentes en Japón, como Basil Hall Chamberlain, Lafcadio Hearn, o en el caso español por Gonzalo Jiménez de la Espada. AlmazÁn TomÁs, V. David (2008): "Una joya bibliográfica hispano-japonesa: los cuentos y leyendas del Japón de Gonzalo Jiménez de la Espada editados como chirimen-bon por T. Hasegawa (Tokio, 1914)”. En: Artigrama, 23. Zaragoza, pp. 781-801.

9 Como hoy sigue pasando hoy gracias a la iniciativa Japan Rail Pass.

10 Leheny, David Richard (2003): The Rules of Play: National Identity and the Shaping of Japanese Leisure. Nueva York: Cornell University Press, p. 59. 
rales y, en el reverso, los anuncios publicitarios de los principales negocios japoneses relacionados con el turismo. A comienzos del siglo XX, en 1907, Japón redactó sus primeras leyes de desarrollo turístico, y el Ministerio de Ferrocarriles además de las cuestiones de transporte comenzó a promover la construcción de hoteles. Las compañías ferroviarias estuvieron interesadas en que este medio de transporte fuera el que emplearan los turistas en sus itinerarios por Japón (como hoy sigue pasando gracias al Japan Rail Pass). Por ejemplo, Japan Traveller's Handy Guide, editado en septiembre de 1919 por Imperial Government Railways es un excelente ejemplo de la calidad de estas guías, profusamente ilustradas con fotografías. En la página del título aparece una vista panorámica de la Estación Central de Tokio. El contenido de esta guía de bolsillo es muy completa. Hay un epígrafe sobre información oficial, tanto del gobierno, del ferrocarril y de la oficina de turismo, así como de las embajadas y consulados extranjeros. Otro apartado útil para el viajero son los consejos prácticos que abordan desde las compras a las tarifas de los jinrikisha. El capítulo de las rutas recomendadas incluyen 1) Tokio y Yokohama 2) alrededores costeros (Kamakura, Enoshima), 3) Hakone, 4) la línea Tōkkaidō, 5) las líneas de Kansai, 6) las líneas de Hokuroku, 7) las líneas de Chūo, 8) las líneas de Sanyō, 9) las líneas de San’in, 10) las líneas en Shikoku, 11) las líneas de Kyūshū, 12) las líneas del noreste de Tokio y 13) las líneas de Hokkaidō. Finalmente, la guía proporciona información detallada de los distintos tipos de tren y sus tarifas, tablas con distancias y un detallado mapa en color. En esencia se trata de propuestas muy parecidas a las que encontramos en la actualidad.

Japanese Government Railways publicó asiduamente folletos con atractivas portadas en color, mapas desplegables sobre la red ferroviaria japonesa también en color, fotografías en blanco y negro de festivales, ceremonias, paisajes, luchas de sumō, representaciones teatrales, grandes budas de bronce, pagodas y vistas urbanas y campestres con textos en inglés. Década tras década, las publicaciones turísticas fueron convirtiendose en valiosas fuentes de información, tanto por el tono y dimensión reducida de los textos como por el propio formato de la guía, adaptada en dimensiones al bolsillo de viajero. Es el caso de Pocket Guide to Japan editada ya en 1939 por la Board of Tourist Industry del Japanese Government Railways, en cuyo subtítulo se especifican los temas que el lector podía encontrar en esta abreviada introducción a la cultura japonesa: With special reference to Japanese custom, History, Industry, Education, Art, Acomplishment, Amusements, etc.

\subsection{Tourist Library}

Sin duda de excepcional interés fue la colección Tourist Library, que exquisitamente editó la Board of Tourist Industry, una agencia creada en 1912 por el Japanese Government Railways. Esta colección estaba formada por pequeños libros de unas cien páginas, con ilustraciones y fotografías de gran calidad. Fueron editados regularmente desde 1934 a 1942, momento en que se interrumpe la publicación por el escenario bélico de la Segunda Guerra Mundial. Aunque en un principio estaba previsto que la colección tuviera cien volúmenes para tratar cien aspectos esenciales de la cultura nipona, finalmente el número quedó en cuarenta, cantidad que nos sigue permitiendo considerar la magnitud de este proyecto editorial. Cada libro tenía carácter monográfico, estaba muy documentado y bien estructurado. Se abordaban temas tan interesantes como la ceremonia del té, el teatro $n \bar{o}$, el sakura, los jardines 
japoneses, la arquitectura, los castillos, los balnearios, la gastronomía, la música, etc. La autoría de estos libros, siempre de especialistas japoneses, es un hecho destacable. Cada volumen de esta colección tenía una elegante portada a color y textos de gran calidad ilustrados con cuidadas fotografías.

Sin ser exhaustivos ${ }^{11}$, presentamos algunos de sus títulos más destacados. El primer título fue The Cult of Tea escrito por Hukukita Yasunosuke, que en realidad era una síntesis de un libro mayor escrito en 1932 por el mismo autor. A esta obra le siguieron Japanese Noh Plays de Nogami Toyoichirō y Sakura de Miyoshi Manabu. La temática de estos títulos ya es toda una declaración de intenciones de los objetivos de esta colección: acercar temas de alta cultura al gran público que visita Japón. Otras importantes obras fueron Hiroshige and Japanese landscape, del crítico de arte Yone Noguchi (1875-1947) y Floral Arts of Japan por el maestro de ikebana Nishikawa Issōtei (1878-1938). El célebre profesor D.T. Suzuki (1870-1966) fue el encargado de la redacción de Japanese Buddhism. Cada ejemplar de la colección tenía como prefacio una nota editorial de una página firmada por el Board of Tourist Industry y el Japanese Government Railways que variaba ligeramente para incluir alguna aclaración, pero que en esencia repetía siempre su propósito de ofrecer a los turistas información sobre la cultura que visitaban ${ }^{12}$. Muchos títulos de esta colección volvieron a ser reeditados en un nuevo impulso de turismo iniciado en la década de los años cincuenta y sesenta. Todavía hoy muchos de estos libros forman parte de las bibliografías académicas de introducción a la cultura japonesa.

También en fechas del expansionismo militar japonés y la ocupación de Manchuria, Japón siguió teniendo una intensa actividad editorial de promoción turística. La asociación de promoción cultural Nippon Bunka Shinkōkai editó en 1937 un excelente libro titulado Beautiful Nippon, ilustrado con excepcionales fotografías tanto en color como en blanco y negro de la vida tradicional japonesa, parques naturales, templos, vistas famosas, puentes, el edificio de la Dieta y otros monumentos, que se completaban con exquisitas xilografías a color, nishiki-e, características de grabado ukiyo-e, con vistas de templos sintoístas y paisajes de Hiroshige. También la encuadernación era a la japonesa y contaba con un lujoso estuche forrado en tela. Se editó en un formato grande, 31 x $46 \mathrm{~cm}$. con 195 páginas. Promocional y propagandístico, pues también aparecían temas militares y deportivos, Beautiful Nippon contaba con textos tanto en japonés como en inglés.

Tras los Juegos Olímpicos de Berlín de 1936, Tokio se preparaba para organizar los próximos, considerándolo un estímulo para el turismo, sin embargo, el ascenso

11 Los títulos de la colección son: $\mathrm{n}^{\circ} 1$ Tea Cult of Japan, $\mathrm{n}^{\circ} 2$ Japanese Noh Plays, $\mathrm{n}^{\circ} 3$ Sakura, n4 Japanese Gardens; $\mathrm{n}^{\circ} 5$ Hiroshige and Japanese Landscapes, $\mathrm{n}^{\circ} 6$ Japanese Drama, $\mathrm{n}^{\circ} 7$ Japanese Architecture, $\mathrm{n}^{\circ} 8$ What is Shinto?, $\mathrm{n}^{\circ} 9$ Castles in Japan, $\mathrm{n}^{\circ} 10$ Hot Springs in Japan, $\mathrm{n}^{\circ} 11$ Floral Art of Japan, $\mathrm{n}^{\circ} 12$ Children's Days in Japan, $\mathrm{n}^{\circ} 13$ Kimono, $\mathrm{n}^{\circ} 14$ Japanese Food, $\mathrm{n}^{\circ} 15$ Japanese Music, $\mathrm{n}^{\circ} 16$ Judo, $\mathrm{n}^{\circ} 17$ Family Life in Japan, $\mathrm{n}^{\circ} 18$ Scenery of Japan, ${ }^{\circ} 19$ Japanese Education, $\mathrm{n}^{\circ} 20$ Floral Calendar of Japan, $\mathrm{n}^{\circ} 21$ Japanese Buddhism, $\mathrm{n}^{\circ} 22$ Odori, n'23 Kabuki Drama, n²4 Japanese Woodblock Prints, $\mathrm{n}^{\circ} 25$ History of Japan, $\mathrm{n}^{\circ} 26$ Japanese Folk-Toys, $\mathrm{n}^{\circ} 27$ Japanese Game of Go, $\mathrm{n}^{\circ} 28$ Japanese Coiffure, $\mathrm{n}^{\circ} 29$ Japanese Sculpture, $\mathrm{n}^{\circ} 30$ Japanese Postage Stamps, $\mathrm{n}^{\circ} 31$ Japan's Ancient Armour, $\mathrm{n}^{\circ} 32$ Angling in Japan, $\mathrm{n}^{\circ} 33$ Japanese Proverbs, $\mathrm{n}^{\circ} 34$ Sumo, $\mathrm{n}^{\circ} 35$ Japanese Birds, n³6 Ainu Life and Legends, n³7 Japanese Family Crests, n³8 Japanese Industrial Arts, n³9 Hand-Made Paper of Japan y n ${ }^{\circ} 0$ Japanese National Character.

12 El inicio de estas notas editoriales incluían la siguiente declaración: "It is a common desire among tourists to learn something of the culture of the countries they visit, as well as to see their beautiful scenery... The Board of Tourist Industry recognizes both the obligation and the difficulty of providing foreign tourists with accurate information regarding the various phases of Japan's culture... By studying the entire series, the foreign student of Japan will gain an adequate knowledge of the unique culture that has evolved in this country through the ages". 
del militarismo hizo que se cancelaran en 1938. Este libro estaba orientado a la promoción de Japón en este contexto. La contraportada mantiene el paralelo entre la tradición del palanquín y el moderno ferrocarril, un tipo de estrategia comunicativa ${ }^{13}$ todavía presente en las miles de guías turísticas que se han editado de Japón y que inciden en este doble carácter que tiene para el visitante la llegada a Japón: el encuentro con un país moderno y avanzado que ha sabido conservar sus atractivas tradiciones.

\subsection{We Japanese}

Las empresas hoteleras se destacaron por su labor de difusión del patrimonio cultural mediante libros con muy cuidadas ediciones, siendo monumental y casi enciclopédica la descripción de costumbres, modas, ceremonias, festivales, artes y artesanías que desde 1934 editó el Hotel Fujiya con el título We Japanese. El nombre completo de la obra es en sí una declaración de intenciones: We Japanese: Being descriptions of many of the customs, manners, ceremonies, festivals, arts and crafts of the Japanese, besides numerous other subjects. La obra tuvo ampliaciones y múltiples reediciones ${ }^{14}$. Una versión final que refundía tres volúmenes fue publicada en 1950 con encuadernación japonesa y un aspecto muy atractivo. We Japanese fue editado por el Fujiya Hotel en Miyanoshita (Hakone) con un prólogo protocolario escrito por su presidente. El Fujiya Hotel había sido fundado por Yamaguchi Sennosuke, un miembro de la célebre misión Iwakura (1871-1873) a Occidente. A su regreso, consciente de la necesidad de habilitar en Japón hoteles como los vistos en Estados Unidos y Europa erigió el Fujiya en Miyanoshita, en el distrito de Hakone, primero con la denominación de ryokan y luego como hotel. Un incendio obligó a reconstruir el hotel en 1883 ya con un estilo arquitectónico de estilo occidental, siendo posteriormente remodelado. En la era Taishō se hizo cargo de la dirección del hotel H.S.K. Yamaguchi (1882-1944), promotor de la edición de la publicación. Durante mucho tiempo We Japanese fue la principal guía turística japonesa para extranjeros editada en Japón. Es por esta razón por la que merece una especial atención su análisis.

Resulta palpable la influencia de Things Japanese de Chamberlain, deuda que se declara en el mismo prefacio de la obra. No obstante es también muy original en sus planteamientos y contenidos. La edición tiene 600 páginas y 889 pequeñas ilustraciones. También es particular en la manera de presentarlos, dedicando una página para cada tópico. El volumen inicial fue redactado para H.S.K. Yamaguchi, presidente del Fujiya Hotel, por Frederic de Garis ${ }^{15}$, mientras que la autoría de los

13 Esta estrategia visual tiene un importante precedente en una sección ilustrada de la popular revista $F \bar{u} z o k u$ Gahō. An illustrated magazine of Japanese lifestyle, que se editó en Tokio desde 1889 y 1916. Dicha sección consistía en un par de ilustraciones en blanco y negro que representaban un oficio antiguo, tradición o elemento del hogar y su versión moderna.

14 Estas reediciones del primer volumen fueron en 1935, 1936, 1937, 1940 y, tras la Segunda Guerra Mundial, en 1946, 1947, 1949 y 1950. El segundo volumen apareció en 1937 y fue reeditado en 1937, 1940, 1947 (en dos ocasiones) y 1950. Finalmente el tercer volumen apareció en 1949 y se reeditó en 1950. En 1950 se hizo la edición conjunta de los tres volúmenes, que se reeditó con éxito hasta 1964.

15 Otros trabajos de este autor fueron GARIS, Frederic de (1922): The hot springs of Japan. Tokio: Japanese Government Railways; GARIS, Frederic de (1926): Japanese landscape gardens. Tokio: Japanese Government Railways; GARIS, Frederic de (1926): The annual cycle of blossoms in Japan. Tokio: Tsukiji Type Foundry; GARIS, 
otros volúmenes fue de Sakai Atsuharu ${ }^{16}$. El primer volumen presenta la bandera nacional, el himno nacional, las diversas eras de la cronología nacional, los volcanes, la población, el monte Fuji, las historias y leyendas (Momotarō, Hagoromo, los tengu y los kappa), el gusto artístico y poético según la estética japonesa (con nociones tan especializadas como el concepto shibui y una presentación de artes ligadas a la naturaleza), las características psíquicas de los japoneses, sus supersticiones, la explicación de algunas costumbres, festivales religiosos y sobre todo aspectos sobre el sintoísmo, budismo y también cristianismo. La obra continúa con un recorrido por los dramas teatrales de Japón, los deportes, sus juegos, las flores, las Bellas Artes, la porcelana, otros productos artesanales, los ainu, las geishas, los balnearios, los proverbios. Incluso hay capítulos que parecen querer aproximarse al lector anglosajón, como los dedicados al descubrimiento de Shakespeare por el público japonés o a la tumba de Williams Adams, el primer inglés en arribar a Japón.

El segundo de los volúmenes aborda el calendario festivo japonés, los balnearios naturales, los terremotos, los monumentos históricos, como castillos, santuarios y templos, así como las esculturas. Una importante sección trata de explicar las características de la conducta japonesa por medio de la vida de algunos personajes ejemplares como Sakura-hime, Hosokawa Gracia, la poetisa Chiyo o Kesa Gozen. Hay también todo un catálogo de objetos que se consideran muy representativos de la cultura nipona, como el puente de Nihonbashi, las campanas y las tsuba, guardas de las espadas. También contiene un apartado de buenas prácticas que informa sobre costumbres y diferencias culturales. Muy atractivas son igualmente las relaciones de santuarios y templos, las tradiciones y legendas, que acercaban al lector a temas como Daruma o los rakan. Desde el punto de vista literario resulta interesante la presentación de Taketori Monogatari como primera novela de Japón. El amor por la naturaleza del pueblo japonés ocupa el último de los apartados sobre historia natural, con descripciones que van desde los gatos, perros y grullas hasta el daikon. Guiños para los turistas norteamericanos en este segundo volumen son los apartados dedicados al comodoro Perry, al embajador Townsend Harris y al presidente Grant, el primero en hacer una visita oficial al país.

Finalmente, el tercer volumen no se articula en diferentes secciones, sino que es una miscelánea que abre un abanico de temas tan interesantes como variopintos. Como muestra diremos que esa parte explica los nengo para contar las eras, los silabarios kana y los kanji, el matrimonio, los pesos y las medidas. También presenta importantes personajes como el emperador Jimmu o el emperador Nintoku. En el plano literario se nos ilustra sobre la importancia del Kojiki, del Man'yōshū y del teatro $n \bar{o}$. En el área de la historia del arte encontramos descripciones de los castillos de Edo y Osaka, del santuario de Hakone y Kompira y del templo budista Hōryūji, entre otros. Completan el índice de contenidos infinitud de anécdotas y curiosidades, desde leyendas de perros y caballos hasta la explicación de cómo son los tabi o calcetines japoneses. Por esta superposición de breves explicaciones, We Japanese sigue siendo como un maravilloso caleidoscopio que ofrece una visión de Japón lo suficientemente variada como para atraer a cualquier lector.

Frederic de (1936): Their Japan. Being brief descriptions of noteworthy phases of Japanese life. Yokohama: Yoshikawa.

16 Este autor también publicó SAKAI, Atsuharu (1949): Japan in a Nutshell. Tokio: Yamagata. 


\section{Conclusiones}

Desde un punto de vista histórico, como complemento a los escritos producidos por los propios viajeros occidentales, hemos de valorar como documentos de excepcional relevancia los escritos que desde la era Meiji se produjeron para hacer accesible Japón a los turistas, pues estos textos condensan tanto las expectativas de los visitantes como la tarjeta de presentación que Japón ha querido ofrecer al mundo desde organizaciones como The Welcome Society of Japan y Japan Tourist Bureau. Una visión panorámica nos indica claramente que algunos importantes agentes del turismo estuvieron directamente implicados en la edición de las guías turísticas japonesas más populares para los extranjeros, utilizando principalmente el inglés como idioma de encuentro con Occidente. El éxito de We Japanese publicado por el Hotel Fujiya es uno de los mejores ejemplos. Por su parte, las compañías de ferrocarril, especialmente Japan Rail, son una de las claves de éxito turístico de Japón, siguiendo así una asentada tradición forjada a lo largo del siglo XX. Todavía hoy, con tanta información en Internet, sigue llamando la atención la calidad de las informaciones y fotografías de la colección Tourist Library editada por Board of Tourist Industry y Japanese Governmet Railways.

En nuestros días, el tren de alta velocidad, Shinkansen, comunica las cuatro grandes islas del archipiélago japonés y los escenarios para profundizar en la cultura japonesa se han multiplicado. Hay un Japón accesible más allá de Tokio, Yokohama, Kobe, Kamakura, Kioto, Osaka y Nara. Existe un listado con las "Cien mejores vistas de Japón de la era Heisei" 17 , configurado en 2009, que presenta muchas novedades con el itinerario que hacían los turistas hace un siglo. El viajero de hoy dispone además de mucha información. Pero en este caso las novedades complementan una visión más "clásica" del turismo japonés, que lejos de desaparecer se mantiene con vigor. En efecto, por su historia y tradición hay una gran continuidad entre el Japón que seducía a nuestros antepasados y el que hoy nos sigue fascinando. Hay un núcleo, presidido por el monte Fuji y jalonado por las capitales históricas, los templos, los santuarios y los jardines. Se trata sobre todo de ese Japón "tradicional" que mantiene unas constantes como destino turístico: sus religiones, festividades, amor por la naturaleza, legado histórico, costumbres, gastronomía, normas de cortesía y etiqueta, etc. Cuestiones que en modo alguno son un envoltorio folklórico de la cultura nipona, sino que son rasgos de su propia identidad.

17 Listado elaborado con más de 640.000 votos en una campaña organizada por el diario Yomiuri Shimbun, con el patrocinio de algunas empresas privadas y la colaboración del Ministerio del Territorio, Infraestructuras, Transporte y Turismo. 